\title{
Performance Appraisal of Non-governmental Organizations: A Discussion on Pakistan 2010 Floods Response and Recovery
}

\author{
A. ALI $^{1 *}$, N. BAIG ${ }^{1}$ AND A. KHAN ${ }^{1}$
}

\begin{abstract}
The paper examines in detail the role of NGOs (Non-governmental Organizations) in response and recovery phase of a disaster. Donors, INGOs (International Non-governmental Organizations) and NGOs work for the betterment of affected community but due to certain shortfalls, the community did not benefit as much as intended. In this research those gray areas are highlighted in detail through field visits and interaction with the community devastated by 2010 floods. Lack of inter-agency cooperation, partnership with inexperienced local NGOs and lack of transparency and accountability mechanisms are those areas which reduce the effectiveness of response and recovery efforts. These gray areas cause loss of precious resources and duplication of efforts which results in increased vulnerability of that particular community.
\end{abstract}

Key words: Disaster; 2010 flood; response; recovery; non-governmental organizations; international non-governmental organizations; community; inter-agency co-operation

In the last week of July 2010, most of the Indus River basin in Pakistan submerged due to torrential rains. Resulting floods severely affected about 20 million people and their property, infrastructure and livelihood along with 1985 deaths and USD9.5 billion economic loss (Andrew et al. 2010).

Floods has destroyed 728192 houses entirely and rendered more than 385325 houses non-residential due to rigorous damages. These damages were mostly visible in districts of Muzafargarh and Rajenpur in Punjab, Nowshera and Dera Ismail Khan in Khyber-PukhtunKhwa, and Jafarabad, Jacobabad, Shikaarpur and Thatta in Sindh. The provision of critical facilities like schools and healthcare centres were severely affected by floods. More than 7600 schools were completely destroyed and needed to be reconstructed while 436 health units were either destroyed or severely damaged
(Maryum et al. 2012). Electric power supply, foods and water supply were interrupted by floods in most parts of the country and destroyed most of the food stocks like wheat and other food stuffs across the country and created shortage of these commodities in the affected areas. Livestock and fisheries were destroyed and tube wells were contaminated and clogged with mud carried by flood water.

In district Nowshera of KPK, Nowshera Kalan is one of the most affected areas in 2010 floods as shown in Figure 1 (Mateeul et al. 2012).

Nowshera Kalan was totally submerged in flood water which rendered more than 700000 peoples homeless in Nowshera. Dead animals and dead bodies were lying in the streets, river and roads and it had a stinging smell in the air.

\footnotetext{
${ }^{1}$ National University of Sciences and Technology, Islamabad, Pakistan

* Corresponding author (e-mail: aliarshad08@yahoo.com)
} 


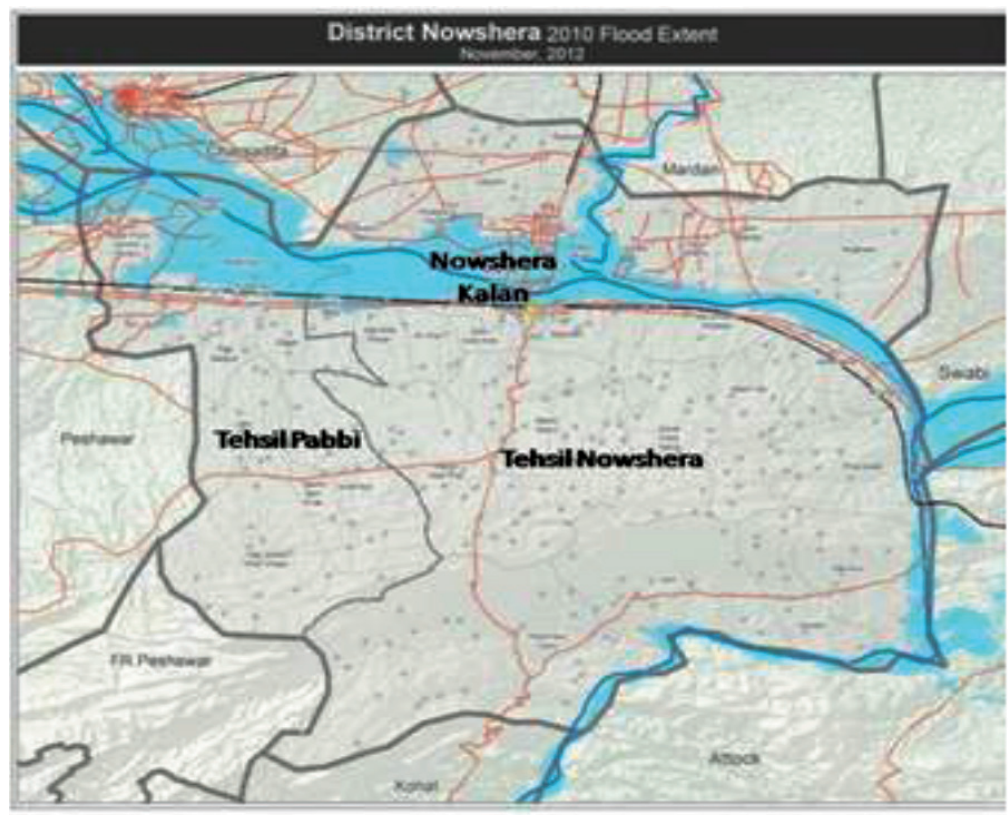

Figure 1. District Nowshera, during the 2010 Flood.

Such widespread destruction was not manageable by the local as well as the national government and request for external intervention was made by the Federal Government to tackle the situation and reduce further losses. As a result, Pakistan received overwhelming response from the international community as well as from their own people living inside and outside from the country. Main stakeholders in disaster response and recovery were International NonGovernmental Organization (INGOs), NonGovernmental Organization (NGOs), United Nations, Military, donors, National Disaster Management Authority (NDMA) / Provincial Disaster Management Authority (PDMA), volunteers and charity organizations as shown in Figure 2. Many INGOs like Medicine Sans Frontier (MSF), MuslimAid UK, United Nations High Commission for Refugees, Norwegian Red Cross, International Federation of Red Cross and Red Crescent, Al-Khidmat Foundation, Ummah Welfare Trust, volunteers from different educational institutions and many others took part in response and recovery of the devastated communities (Ali et al. 2012).

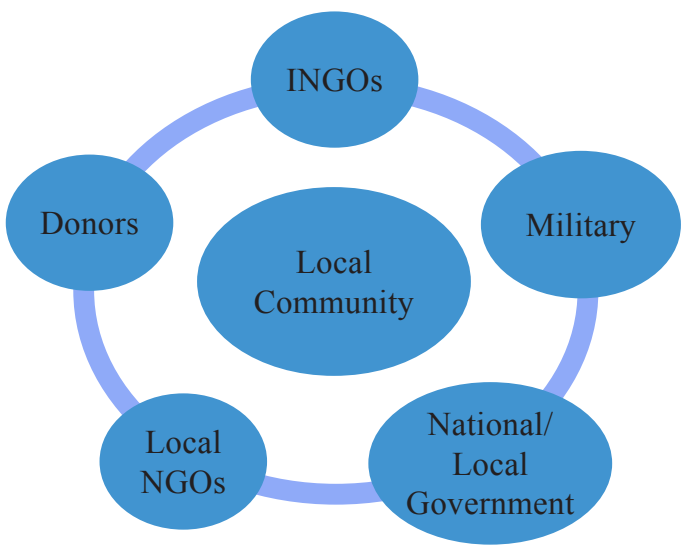

Figure 2. Different stakeholders of 2010 Flood.

The objective of this research is to ascertain that the efforts carried out by NGOs to respond to the emerging situation to build back better and resulting social and economic impacts on that community is apprised. 


\section{METHODOLOGY}

The methodology adopted was extracted from various studies covered by the subject. The main sources of primary data were field visits and face to face interviews of the key respondents who were either worked as volunteers or affected by the flood and remained present throughout relief and recovery phases. The whole area has been divided into urban and rural sub-areas. Urban area consists of 14 localities while rural area consists four villages. Key respondents include two to four volunteers (male and female) and eight to ten affected households in each urban locality and from each village. Time span for the primary data collection was 8 months in post-disaster scenario. Weekly field visits were arranged each month to collect and record primary data. Secondary data were received from different local and national newspapers in post-disaster scenario for one year and from progress reports of those organizations who took part in response and recovery in the target area (Adnan et al. 2011, Junqiang et al. 2011). The information collected from these reports of different NGOs who worked in the target area on livelihood improvement, rehabilitation/ reconstruction, WATSAN, WASH (water, sanitation and hygiene) were compared with ground realities obtained from primary data to assess the net positive impact of huge public spending by NGOs on affected community lives.

\section{RESULTS AND DISCUSSION}

This research indicates that the work carried out by most of the locals NGOs is not upto satisfaction of the effected community as it is visible from the on-ground realities and interaction with them. The analysis of primary data and different news items and its comparison with reports prepared by different NOGs who worked in the affected areas magnify the following gray areas which contributed to the low level efficiency and effectiveness of these humanitarian organizations.

\section{Lack of Inter-agency Co-ordination}

NGOs who take part in disaster response and help victims, have different backgrounds and motivation. They are the main source of providing microfinance and other services but according to their own strategies and missions (Khan et al. 2009). Due to the strict adherence to their own objectives and strategies, they do not co-ordinate with each other and results in misuse of scarce and precious resources. For example, in the 2010 floods, MSF and UNHCR both have provided Non-Food Items (NFIs) to the same population and resulted in the demand and supply imbalance i.e. NFIs were provided more than the actual demand.

\section{Inexperienced NGOs}

Due to the inexperienced NGOs who are taking part in disaster response can further complicate the situation by not co-operating and co-ordinating with other NGOs and or producing poor-quality work. It is evident from the field visits and respondent views that most of the NGOs who took part in WATSAN (water and sanitation) constructed hand pump on such points where it was not needed. Those NGOs who were involved in the recovery phase have provided low quality construction materials which resulted in bad word of mouth for NGOs.

\section{Lack of Community-based Representative Organizations}

Most of the NGOs work with and through local community-based organizations but in developing countries, the influence of a community dictates NGOs which does not represents a community will. The respondents in the target area showed dissatisfaction over the behaviour of the staff of NGOs, who were acting according to influence by neglecting the needy people (Asif et al. 2013). In the relief phase, relief items were distributed through these influential ones in which they served their own nears and dears the most. 


\section{Transparency and Accountability in Recovery Phase}

In the reconstruction phase, design and implementation of reconstruction programmes are very important but should be imbed with accountability and transparency. These programmes must make sure that an effective complaint mechanism is in place for the neglected people. Interviews with effected people revealed that in the reconstruction phase, employees of NGOs misused their powers and reconstructed houses of those people who did not deserve just for the sack of few pennies. Due to non-availability of a complaint mechanism, the deserving people were left in the lurch.

Lacking co-ordination and marred by ad-hoc nature, the reconstruction efforts lack strategic frame work. People also complained that in some cases two or three NGOs constructed houses of a single affected one which shows the ad-hoc behaviour and the lack of co-ordination among the responding agencies.

\section{INGO's Partnership with Local NGOs}

INGO's implement their projects using different strategies. The most commonly used strategy is building partnerships with local NGOs. The aim through such partnership is, they want to reach the poorest, neglected and the grass root. But, the INGOs provide resources to these local NGOs without accountability and transparency as indicated by field visits and background discussion with local people. For example, the German Society for International Cooperation provided financial assistance through the Sarhad Rural Support Program for WATSAN to each community based organization according to the population but on ground nothing has been done with the same amount. Just wall chalking and banners were prepared by each Community-basedorganizations to eye wash the donor and not more than that (Kristin 2010).

\section{Delay in Starting of Recovery Phase}

Delay in starting recovery or reconstruction may result in misuse of resources. Most of the effected people reconstruct their dwellings as they cannot wait for a long time for aid due to cultural constraints. After a few months, these NGOs do not find houses to reconstruct and as a result, the NGOs staff constructs houses for those who does not deserve by acquiring monetary benefits.

\section{Under-estimating Local Capabilities}

Under-estimating local capabilities, the behaviour of dependency and misuse of resources could be the result of an international aid. The background discussion with many volunteers and locals revealed that many NGOs under-estimated the capabilities of effected people and provided international aid in such a manner which created the behaviour of dependency and misuse and people became lazy to work. At last the government removed the shelters provided to the people after flood.

\section{CONCLUSION}

After any disaster, there are too many local NGOs spring out to respond to the emerging situation. These local NGOs lack resources and expertise to handle such a complex situation. They depend on various donors and INGOs. Donors and INGOs build partnership to reach the most deserving and the gross-root level. Due to inexperience and lack of resources, these local NGOs become the source of problem and bad reputation for the whole humanitarian community. Misuse of resources and mistrust among the affected community could be the result of depending on these inexperienced NGOs. These problems can be best addressed through scrutinizing these local NGOs for their capabilities and past experiences before any partnership is built with them.

Date of submission: January 2013

Date of acceptance: March 2014 


\section{REFERENCES}

Asgary, A, Anjum, MI \& Azimi, N 2012, 'Disaster recovery and business continuity after the 2010 flood in Pakistan: case of small businesses', International Journal of Disaster Risk Reduction, vol. 2, pp. 46-56.

Asif, MK, Haneef, M, Anwar, SK \& Tazeem T 2013, 'Debris-flow hazards on tributary junction fans, Chitral, Hindu Kush Range, Northern Pakistan', Journal of Asian Earth Sciences, vol. 62, pp. 720-733.

Baqir, M, Sobani, ZA, Bhamani, A, Bham, NS, Sidra Abid, Javeria Farook \& Beg, MA 2012, 'Infectious diseases in the aftermath of monsoon flooding in Pakistan', Asian Pacific Journal of Tropical Biomedicine, vol. 2, no. 1, pp. 76-79.

Haq, M, Akhtar, M, Muhammad, S, Paras, S \& Rahmatullah, J 2012, 'Techniques of Remote Sensing and GIS for flood monitoring and damage assessment: a case study of Sindh province, Pakistan', The Egyptian Journal of Remote Sensing and Space Science, vol. 15, no. 2, pp. 135-141.
Junqiang, Xia, Roger, A. Falconer, Lin, B \& Tan, G 2011, 'Numerical assessment of flood hazard risk to people and vehicles in flash floods', Environmental Modelling \& Software, vol. 26, no. 8, pp. 987-998.

Kerr, AC, Khan, M, Mahoney, JJ, Nicholson, KN, Hall, CM 2010, 'Late Cretaceous alkaline sills of the south Tethyan suture zone, Pakistan: initial melts of the Réunion hotspot?', Lithos, vol. 117, no. 1-4, pp. 161-171.

Khan, MJ, Razzaq, A, Khattak, MK \& Garcia, L 2009, 'Effect of different pre-sowing water application depths on wheat yield under spate irrigation in Dera Ismael Khan District of Pakistan,' Agricultural Water Management, vol. 96 , no. 10 , pp. 1467-1474.

Solberg, K 2010, 'Worst floods in living memory leave Pakistan in paralysis', The Lancet, vol. 376, no. 9746, pp. 1039-1040.

Tahir, AA, Chevallier, P, Arnaud, Y, Luc Neppel, L \& Ahmad, B 2011, 'Modeling snowmelt-runoff under climate scenarios in the Hunza River basin, Karakoram Range, Northern Pakistan', Journal of Hydrology, vol. 409, no. 1-2, pp. 104-117. 